\title{
Electromagnetic Vibration Energy Harvesting for Railway Applications
}

\author{
S. Bradai ${ }^{1,2 *}$, S. Naifar ${ }^{l, 2}$, C. Viehweger ${ }^{l}$, O. Kanoun ${ }^{l}$ \\ ${ }^{1}$ Dept. of Electrical Engineering and Information Technology, Technische Universität Chemnitz, Germany \\ ${ }^{2}$ Dept. of Mechanical Engineering, National School of Engineers of Sfax, University of Sfax, Tunisia
}

\begin{abstract}
Safe localization of trains via GPS and wireless sensors is essential for railway traffic supervision. Especially for freight trains and because normally no power source is available on the wagons, special solutions for energy supply have to be developed based on energy harvesting techniques. Since vibration is available in this case, it provides an interesting source of energy. Nevertheless, in order to have an efficient design of the harvesting system, the existing vibration needs to be investigated. In this paper, we focus on the characterization of vibration parameters in railway application. We propose an electromagnetic vibration converter especially developed to this application. Vibration profiles from a train traveling between two German cities were measured using a data acquisition system installed on the train's wagon. Results show that the measured profiles present multiple frequency signals in the range of $10 \mathrm{to} 50 \mathrm{~Hz}$ and an acceleration of up to $2 \mathrm{~g}$. A prototype for a vibration converter is designed taking into account the real vibration parameters, robustness and integrability requirements. It is based on a moving coil attached to a mechanical spring. For the experimental emulation of the train vibrations, a shaker is used as an external artificial vibration source controlled by a laser sensor in feedback. A maximum voltage of $1.7 \mathrm{~V}$ peak to peak which corresponds to a maximum of $10 \mathrm{~mW}$ output power where the applied excitation frequency is close to the resonant frequency of the converter which corresponds to $27 \mathrm{~Hz}$.
\end{abstract}

\section{Introduction}

Contrarily to passenger's train, electricity is not available in all carriages of freight trains. However, there is a growing need to install several sensors in different wagons of the train in order to measure different parameters such as temperature and position, etc.... In such application, vibration is one of the promising source in this case to power sensors. Nevertheless, to harvest energy form such source is not easy because of its irregularity in term of characteristic frequency and amplitude.

Currently, several energy harvestings for railway are developed. Mainly two mechanisms are used to convert this mechanical energy to electrical one which are piezoelectric [1-3] and electromagnetic principles [4, 5].

[6] developed a piezoelectric energy harvesting system with magnetic pendulum movement able to generate $40.245 \mu \mathrm{W} / \mathrm{cm}^{3}$ in passenger's train. Using similar principle, [7] proposed a piezoelectric converter based cantilever beam, it generates $19.64 \mathrm{Mw}$ when 8 permanent magnets were added as tip mass on the cantilever for an operating commercial high-speed Korean train with a speed greater than $300 \mathrm{~km} / \mathrm{s}$. In [8], a piezoelectric converter using patch-type and stack-type inducing energy by passing trains is developed. Results prove, the converter harvests energy in the range of $\mathrm{mJ}$ from track vibration. Another type of piezoelectric converter placed on the bottom of rail track is realized by [9]. The system is based on the use of piezoelectric films and harvests $1 \mathrm{~mW}$ of power.

Other research focused on the development of vibration converter based on electromagnetic principle. [10] developed an electromagnetic converter which is placed near the rail. Once the train passes, energy will be generated through the coil fixed near the rail. [11] Another method is used in rail to harvest energy, it uses a gear and rack mechanism, and maintaining the rotational motion of the generator with roller clutches and a flywheel. An energy outcome in the range of $\mathrm{W}$ is reached. Another architecture based on the use of spherical magnet and a spiral coil placed around a central disc magnet is realized in [12] and implemented in train. It generates an average power of $0.1 \mathrm{~mW}$ in the case of attracting field (discs and spherical magnets have same polarization) and $0.65 \mathrm{~mW}$ for opposing field (discs and spherical magnets have opposite polarization).

These solutions are useful to profit from train vibration to power systems placed on the rail but not adequate to

\footnotetext{
* Corresponding author: sonia.bradai@s2013.tu-chemnitz.de
} 
be placed on the train wagons. The aim of this work is to develop a solution that can be implemented in train wagons to harvest energy from existing vibration.

In this work, an electromagnetic converter able to be placed on train wagons is proposed. This paper is organized in 3 sections. As first, trains vibration is measured and characterized in real time in term of acceleration and frequency. Section 2 is devoted to the design of an electromagnetic converter adequate for implementation in train. At the end, the converter is realized and tested under random vibration profiles.

\section{Railways vibration characteristics}

Vibration profiles from a freight train travelling from Leipzig to Hamburg and back were recorded. For this purpose, a data logger was designed and was attached to one of the train carriages as shown in Fig. 1. It processes the signals from an acceleration sensor and saves them in the form of profiles. The vibration measurement was carried out with two acceleration sensors, which operate with a sampling frequency of $100 \mathrm{~Hz}$. According to sampling theorems, frequencies up to $50 \mathrm{~Hz}$ can thus be measured.

The measurement was done for the three axes; $X$, axis in the direction of travel, $Y$ horizontal axis orthogonal to the direction of travel and the $\mathrm{Z}$ axis in the height. However, vibration along the $\mathrm{Z}$ axis have showed the greatest acceleration amplitudes and then only data along this axis will be considered.

After collecting of the measured data from the field test, the profiles were analyzed and investigated and promising ones were identified.

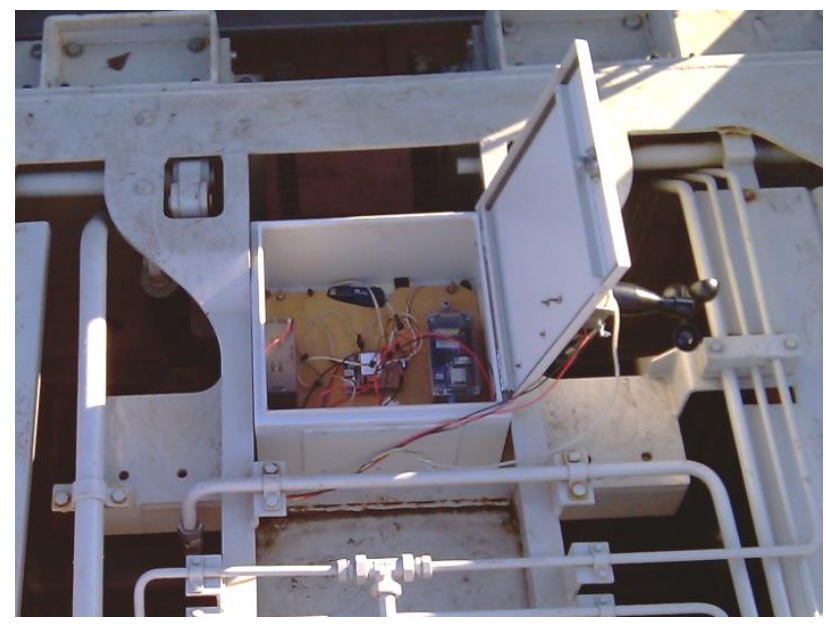

Fig. 1. Data logger attached to one of the train carriages for vibration measurement.

\subsection{Measured acceleration}

Fig. 2 presents an example of measured acceleration profiles for 1 hour of travel. It can be seen that the maximum measured acceleration is in the range of $2 \mathrm{~g}$, which corresponds to an acceleration of about $20 \mathrm{~m} / \mathrm{s}^{2}$.

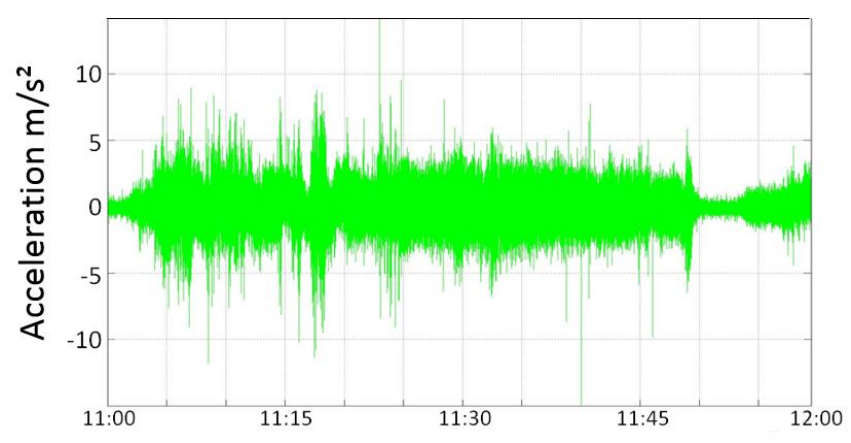

Fig. 2. Example of measured vibration profile for 1 hour of travel.

On average, the amplitudes are about $3 \mathrm{~m} / \mathrm{s}^{2}$.

\subsection{Frequency analysis}

Two selected acceleration profiles were processed and converted to amplitude responses in order to be able to regenerate the measured excitations using an artificial vibration source. In order to investigate the presented frequencies in the measured profiles, Fourier spectrum for one-minute vibration is presented in Fig.3.

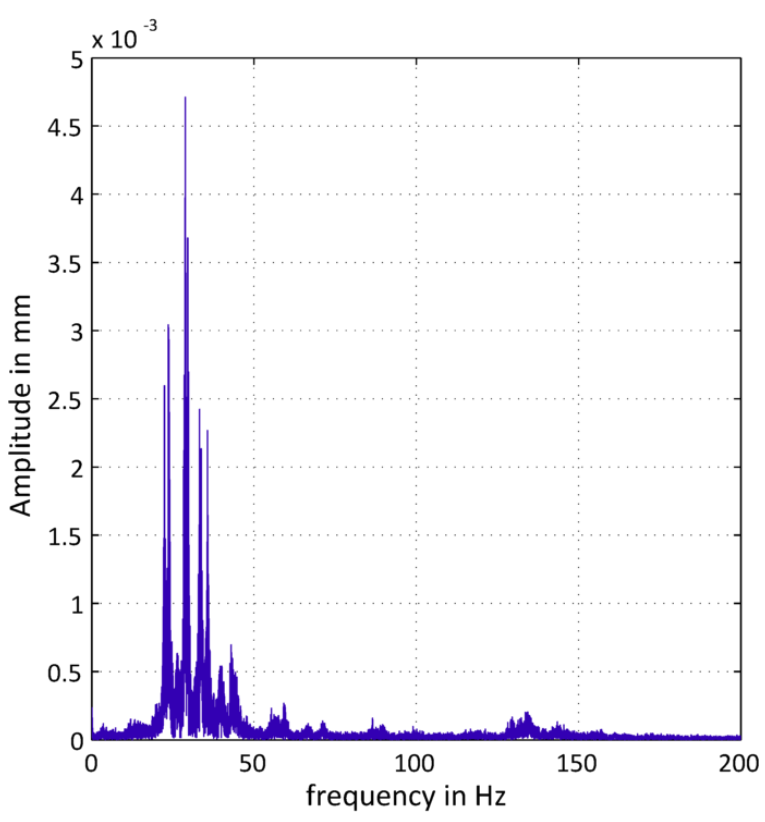

Fig. 3. Fourier transforms performed on an example for oneminute vibration profile.

Results indicates that most of the presented frequencies in the examined profile are in the range of $20 \mathrm{~Hz}$ to 40 $\mathrm{Hz}$. Furthermore, the main measured peak frequency is about $29 \mathrm{~Hz}$. Based on these results and the state of the art of vibration converter [13], electromagnetic principle is one of the most promising solution for this frequency range. Therefore, in the following design of an electromagnetic converter is proposed to harvest energy from such vibration source. 


\section{Design}

This section is devoted to the design of an electromagnetic vibration converter suitable for the presented source in section 2. In general, an electromagnetic converter is basically formed with magnets and coil moving relative to each other in order to generate a certain energy. To ensure the system functionality, two main concepts are used for the converter design. The first one consists of the use of mechanical spring where a coil or a magnet is attached and moving relative to the applied excitation (Fig.4. (a)). The second concept is based on the use of magnetic spring principle to transmit the applied vibration. In this case, the coil is fixed surrounding the moving magnet from the magnetic spring (Fig.4. (b)).

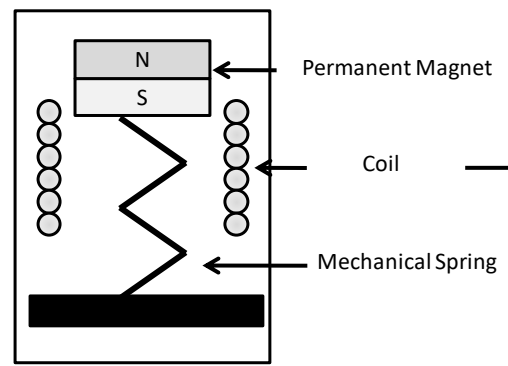

(a)

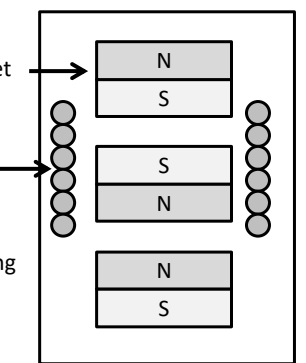

(b)
Fig. 4. Electromagnetic converter architecture based (a) mechanical spring, (b) magnetic spring.

For the magnetic spring architecture, the main advantage is to have a system working for larger frequency bandwidth due to the nonlinearity of the system. However, this architecture has a functional limitation that such solution cannot be implemented in a metallic environment because of the use a moving magnet. Instead of that, the mechanical spring architecture can be used for such environment by attaching the coil to the mechanical spring using a non-magnetic mechanical spring. Taking into account the application, the mechanical spring using moving coil will be adopted in order to be implemented in a magnetic environment.

In this case, the frequency bandwidth for the converter will be limited. Therefore, for the design, the resonant frequency of the converter should be well chosen in order to harvest maximum of the energy relative to the applied random excitation measured in railway. The proposed design is presented in Fig.5. It is formed with a mechanical spring where a coil is attached. Magnets are placed inside the coil. The main advantages of this proposed architecture are the possibility to be placed in magnetic environment, its compactness and the possibility to tune the resonant frequency by changing the stiffness spring or by using an added mass. At the end, the design overcomes one of the main limitation of the moving coil by avoiding the contact between the coil wire with the mechanical spring which leads to a better robustness for the converter.

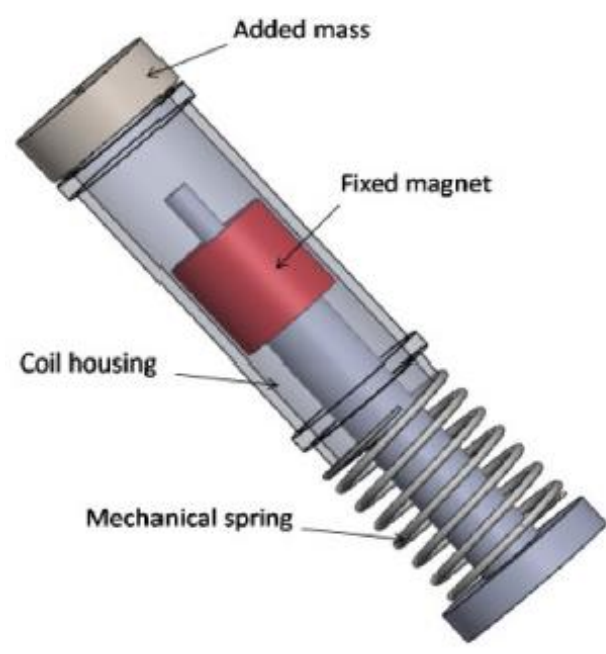

Fig. 5. Proposed mechanical design for the electromagnetic converter.

Table 1 presents the different parameters characteristics selected for the proposed converter design robustness for the converter.

Table 1. Specification of the proposed converter.

\begin{tabular}{|c|c|}
\hline Parameter & Value \\
\hline Housing size & Diameter x length: $14 \times 80 \mathrm{~mm}^{2}$ \\
\hline $\begin{array}{c}\text { Mechanical spring } \\
\text { stiffness }\end{array}$ & $0.06 \mathrm{~N} / \mathrm{mm}^{2}$ \\
\hline Magnet size & $6 \times 2 \times 2 \mathrm{~mm}^{3}$ \\
\hline Magnets number & 10 \\
\hline Coil length & $20 \mathrm{~mm}$ \\
\hline $\begin{array}{c}\text { Copper wire } \\
\text { thickness }\end{array}$ & $0.1 \mathrm{~mm}$ \\
\hline $\begin{array}{c}\text { Number of turns } \\
\text { Coil resistance }\end{array}$ & 600 \\
\hline $\begin{array}{c}\text { Total mass acting } \\
\text { on the spring }\end{array}$ & $35 \Omega$ \\
\hline
\end{tabular}

\section{Experimental results}

In the following the proposed converter was realized and tested under some real profiles measured in train. The profiles are reproduced by an electrodynamic shaker. The resonant frequency of the harvester was determined experimentally using a harmonic excitation for $1 \mathrm{~mm}$ excitation amplitude. Results indicates that the designed converter which has an inner resistance of $35 \Omega$ can generate $0.72 \mathrm{~V}$ as open circuit peak to peak voltage at $27 \mathrm{~Hz}$. 
Experiment investigations were carried out using two vibration amplitude profiles of 30 seconds length each as shown in Fig. 6 (a) and (c). The harvester was fixed on the top of the shaker and the amplitude of vibration was measured by a displacement laser sensor. Fig. 6 (b) and (c) present the measured open circuit voltages corresponding to profiles given in Fig. 6 (a) and (c) respectively.

For the profile (A), the maximum amplitude is around $0.5 \mathrm{~mm}$ while the average amplitude is around $0.3 \mathrm{~mm}$. In this case, the maximum output voltage is around $1.7 \mathrm{~V}$ peak to peak voltage (Fig.6. (b)). It can be seen that the maximum voltage is reached not at the maximum applied amplitude displacement. This can be explained

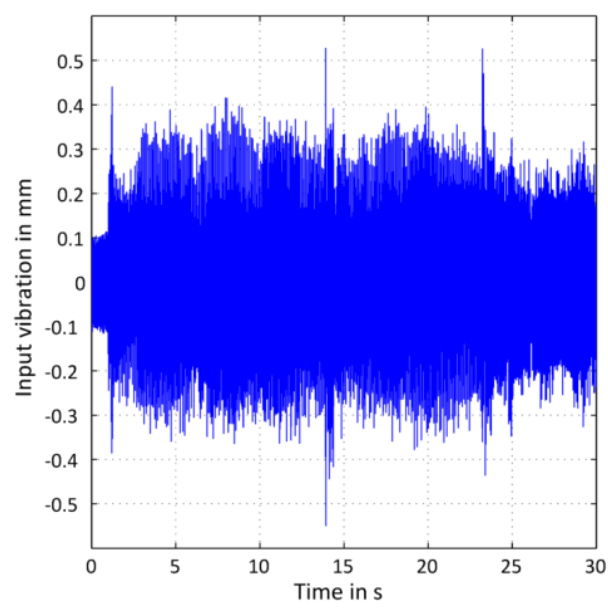

(a)

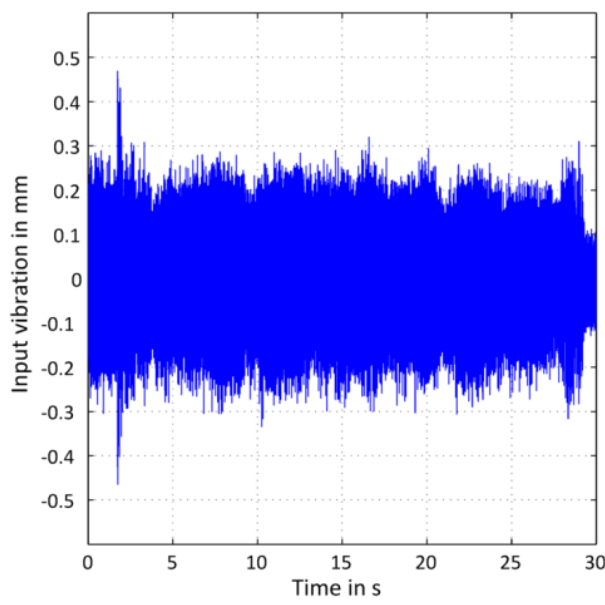

(c) by the effect of the corresponding frequency for each cycle.

For the profile (B), the maximum amplitude is around $0.45 \mathrm{~mm}$ while the average amplitude is around $0.2 \mathrm{~mm}$. $1.2 \mathrm{~V}$ peak to peak voltage is the maximum reached output voltage (Fig.6. (d)). This voltage is achieved for the maximum applied amplitude. This means that for this cycle, the applied frequency is close to the resonant frequency of the converter.

It can be seen that the maximum voltage is reached at the maximum applied amplitude displacement. This can be explained by the effect of the corresponding frequency for each cycle.

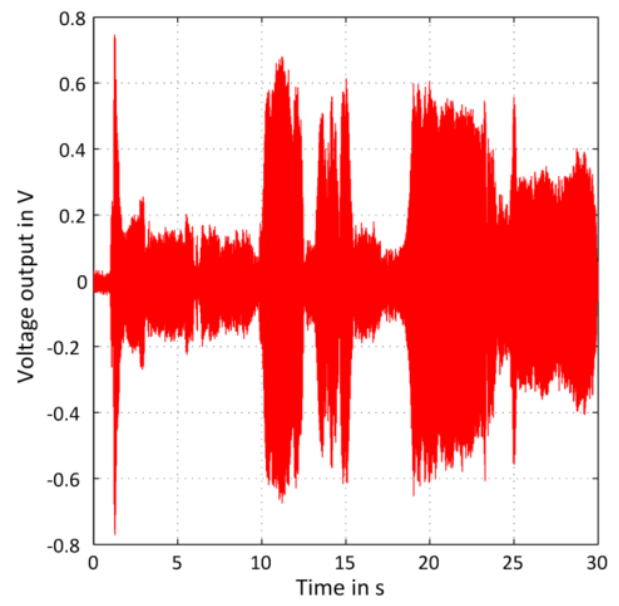

(b)

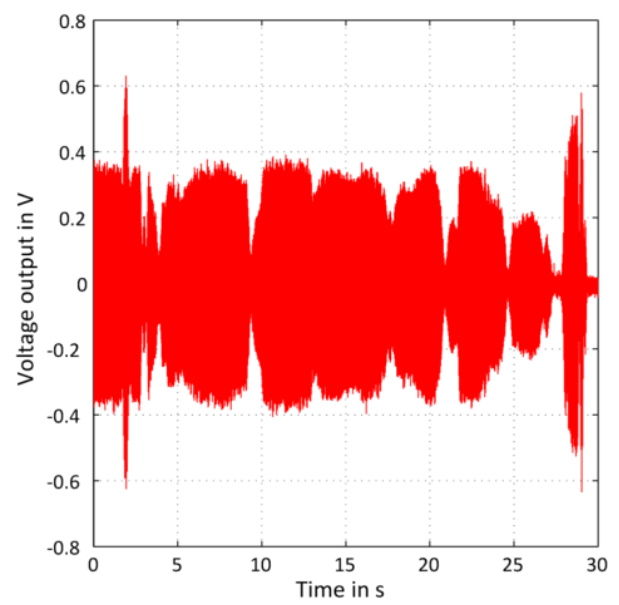

(d)

Fig. 6. (a), (c) applied random excitation for the converter, (b), (d) generated voltage from the converter. Profile A (a), (b), profile B (c), (d)

\section{Conclusion}

In this work, an electromagnetic vibration converter is investigated in order to convert mechanical vibration from railway to useful energy. Vibration profiles were measured in train travelling between two German cities.
Promising acceleration profiles were identified and characterized. The measured profiles are characterized by an acceleration amplitude up to $10 \mathrm{~m} / \mathrm{s}^{2}$ and a frequency range varying from 20 to $40 \mathrm{~Hz}$. Measured profiles are regenerated using an electrodynamic shaker and tested on the proposed converter. Results indicate that a maximum of $1.7 \mathrm{~V}$ peak to peak voltage which corresponds to a maximum of $10 \mathrm{~mW}$ output power can 
be reached for specific cycle where the frequency is close to the resonant frequency of the converter. An average voltage of $1.2 \mathrm{~V}$ peak to peak can be generated for an applied random excitation up to $1 \mathrm{~mm}$ of amplitude and for a frequency range from 20 to $40 \mathrm{~Hz}$.

\section{References}

1. Mouapi, A., Hakem, N., Kandil, N., \& Kamani, G. V., Energy harvesting design for autonomous Wireless Sensors Network applied to trains. In 2016 IEEE International Ultrasonics Symposium (IUS), (pp. 1-4), 2016.

2. Wischke, M., Masur, M., Kröner, M., \& Woias, P., Vibration harvesting in traffic tunnels to power wireless sensor nodes. Smart Materials and Structures, 20(8), 085014, 2011.

3. Li, J., Jang, S., \& Tang, J., Optimization of piezoelectric energy harvester for wireless smart sensors in railway health monitoring. In Proc. of SPIE, Vol. 8692, pp. 86924L-1, 2013.

4. Gao, M., Wang, P., Cao, Y., Chen, R., \& Cai, D., Design and Verification of a Rail-Borne Energy Harvester for Powering Wireless Sensor Networks in the Railway Industry. IEEE Transactions on Intelligent Transportation Systems, 18(6), 15961609, 2017.

5. Bradai, S., Naifar, S., Keutel, T., \& Kanoun, O., Electrodynamic resonant energy harvester for low frequencies and amplitudes. In 2014 IEEE International Instrumentation and Measurement Technology Conference (I2MTC) Proceedings, pp. 1152-1156, 2014.

6. Cho, J. Y., Jeong, S., Jabbar, H., Song, Y., Ahn, J. H., Kim, J. H., ... \& Sung,. Piezoelectric energy harvesting system with magnetic pendulum movement for self-powered safety sensor of trains. Sensors and Actuators A: Physical, 250, 210-218, (2016).
7. Song, D., Yang, C. H., Hong, S. K., Kim, S. B., Woo, M. S., \& Sung, Feasibility study on application of piezoelectricity to convert vibrations of Korea Train eXpress. In Applications of Ferroelectrics held jointly with 2012 European Conference on the Applications of Polar Dielectrics and 2012 International Symp Piezoresponse Force Microscopy and Nanoscale Phenomena in Polar Materials (ISAF/ECAPD/PFM), (2012, July).

8. Wang, J., Shi, Z., Xiang, H., \& Song, G, Modeling on energy harvesting from a railway system using piezoelectric transducers. Smart Materials and Structures, 24(10), 105017, (2015).

9. Nelson, C. A., Platt, S. R., Albrecht, D., Kamarajugadda, V., \& Fateh, M, Power harvesting for railroad track health monitoring using piezoelectric and inductive devices. In Proc. SPIE Vol. 6928, pp. 69280R-69280R, 2008.

10. Z. F. Mian, 2009, Wireless railroad monitoring US patent $12 / 493,789$.

11. Wang J J, Penamalli G and Zuo L, Electromagnetic energy harvesting from train induced railway track vibrations 2012 IEEE/ASME Int. Conf. on Mechatronics and Embedded Systems and Applications (MESA) pp 29-34, 2012.

12. Hart, G., Moss, S., Nagle, D., Jung, G., Wilson, A., Ung, C., ... \& Crew, G., Vibration Energy Harvesting for Aircraft, Trains and Boats. In Proceedings of Acoustics, 2013.

13. Naifar, S., Bradai, S., Viehweger, C., \& Kanoun, O., Survey of electromagnetic and magnetoelectric vibration energy harvesters for low frequency excitation. Measurement, 106, 251-263, 2017. 